\title{
Prospective study of dietary patterns and colorectal cancer among Singapore Chinese
}

\author{
LM Butler ${ }^{*, I}, \mathbf{R}$ Wang ${ }^{2}$, W-P Koh ${ }^{3}$ and MC Yu ${ }^{2}$ \\ 'Division of Epidemiology, Department of Public Health Sciences, University of California-Davis, Davis, CA 956 I6, USA; ${ }^{2}$ The Masonic Cancer Center, \\ University of Minnesota, Minneapolis, MN 55455, USA; ${ }^{3}$ Department of Community, Occupational and Family Medicine, National University of \\ Singapore, Singapore 117597, Singapore
}

\begin{abstract}
An influence of Western diet and lifestyle factors observed among Singapore Chinese may contribute to the population's marked rise in colorectal cancer incidence over the past two decades. Thus far, however, there is little evidence for individual nutrients and foods as major contributing factors in this population. We evaluated whether patterns of food intake were associated with colorectal cancer in a population-based cohort of 61,321 Singapore Chinese that was established in 1993-98. Two dietary patterns, meat-dim sum and vegetable-fruit-soy, were previously identified by principal components analysis using baseline dietary data from a validated I 65-item food frequency questionnaire. As of 3 I December 2005, 96 I incident colorectal cancer cases were diagnosed. Proportional hazards regression was used to calculate adjusted hazard ratios. Using nearly 10 years of follow-up data, we observed no association with either the meat-dim sum or vegetable-fruit-soy pattern for colorectal cancer. In conclusion, neither individual nutrients or foods nor dietary patterns appear to explain the rise in colorectal cancer among Singapore Chinese population.

British Journal of Cancer (2008) 99, I5 I I- 15 I6. doi: I0.1038/sj.bjc.6604678 www.bjcancer.com
\end{abstract}

Published online 23 September 2008

(c) 2008 Cancer Research UK

Keywords: colorectal cancer; diet; dietary patterns; principal components analysis; prospective cohort; Singapore Chinese

Coinciding with gaining political independence in 1965, Singapore, a country of 4 million people, mostly of Chinese ethnicity experienced tremendous economic growth (Ministry of Trade and Industry, 2005). Along with the rise in industrialisation and urbanisation there was a shift in the major causes of death from infectious diseases to 'lifestyle' diseases common in Western societies, such as cancer, cardiovascular disease, and stroke (Ministry of Health, 2006). This shift was also evident with cancer trends, where cancers associated with infection, such as stomach, nasopharynx, liver, have been decreasing in incidence, whereas cancers of the prostate, breast, and colorectum have been on the rise (Seow et al, 2004). Colorectal cancer, in particular, has increased by over $120 \%$ among men and women in the past two decades (Wong and $\mathrm{Eu}, 2007$ ), approaching the incidence rates seen among US Chinese (McCracken et al, 2007).

Using data from a prospective cohort of 63257 Singapore Chinese, we have investigated diet by analysing associations with individual nutrients and foods thought to be aetiologically relevant to colorectal cancer (World Cancer Research Fund/American Institute for Cancer Research, 2007). While valuable, this strategy probably did not capture the complex interactions between individual nutrients and their correlations with other dietary (Randall et al, 1990; Kant et al, 1991), lifestyle (Slattery et al,

*Correspondence: Dr LM Butler, Division of Epidemiology, Department of Public Health Sciences, One Shields Avenue (DaVinci), Davis, CA 956 I6, USA; E-mail: Imbutler@ucdavis.edu

Received 28 July 2008; revised 26 August 2008; accepted 26 August 2008; published online 23 September 2008
1999; Maskarinec et al, 2000), and sociodemographic patterns (Gex-Fabry et al, 1988; Lv and Cason, 2004) that may confound associations with colorectal cancer. This is one plausible explanation for the more consistent epidemiologic findings with dietary patterns and colorectal cancer, compared to those with nutrients and foods. For example, several prospective studies support a positive association with dietary patterns characterised by red meat, potatoes, sweets, and fried foods (Fung et al, 2003; Dixon et al, 2004; Kesse et al, 2006; Flood et al, 2008). However, few data address dietary patterns among Chinese populations in relation to colorectal cancer (Seow et al, 2002), and to our knowledge, none have evaluated these associations in a prospective study.

\section{MATERIALS AND METHODS}

The design of the Singapore Chinese Health Study has been previously described (Yuan et al, 2003). The cohort consisted of 63257 men and women recruited between April 1993 and December 1998, from permanent residents or citizens of Singapore aged 45-74 years, and who resided in government-built housing estates ( $86 \%$ of the Singapore population resided in such facilities). We restricted the study to individuals belonging to the two major dialect groups of Chinese in Singapore: the Hokkiens and the Cantonese. Participants completed a baseline in-person interview that elicited information on diet, demographics, current physical activity, reproductive history (women only), occupational exposure, and medical history. For these analyses, we used data from the 61321 individuals who did not have a history of cancer diagnosis at baseline. The Institutional Review Boards at the 
University of Minnesota and the National University of Singapore have approved this study.

Incident colorectal cancer cases and deaths among cohort members were identified by record linkage of the cohort database with the population-based Singapore Cancer Registry and the Singapore Registry of Births and Deaths. The nationwide cancer registry has operated since 1968 and is comprehensive in its ascertainment (Parkin et al, 2003). To date, only 17 cases were known to be lost to follow-up due to migration out of Singapore. As of 31 December 2005 (an average of 9.8 years of follow-up), 961 cohort participants developed invasive colorectal cancer (591 colon, $370 \mathrm{rectal} /$ rectosigmoid cancers).

At baseline, a 165-item quantitative food frequency questionnaire, developed for and validated in this population, was administered to assess usual diet over the past year (Hankin et al, 2001). Principal components analysis among the baseline cohort $(N=63257)$ was used to identify dietary patterns from the food frequency responses, details of which have been reported (Butler et al, 2006). Briefly, the number of components retained for orthogonal rotation was based primarily on examination of scree plots and factor interpretability, but eigenvalues $(>1.0)$ and percent variance explained were also considered (Hatcher, 1994). For each component, a score was computed as a linear composite of the foods with meaningful loading scores (e.g., $\geqslant 0.30$ ). Scores were calculated by taking the unweighted sum of standardised frequencies of intake for each food associated with the pattern, then dividing them into quartiles based on the distribution of the baseline cohort. We labelled the two distinct dietary patterns: 'vegetable-fruit-soy' and 'meat-dim sum' (See Appendix Table A1). Briefly, the vegetable-fruit-soy pattern was characterised by vegetable, fruit, and soyfood intake; of the 32 foods included in the pattern, 23 were vegetables, five were soyfood items, and four were fruit items. The meat-dim sum pattern contained 31 food items, predominantly chicken, pork, fish, rice and noodle dishes, and preserved foods. Eleven of the nineteen dim sum or snack items on the questionnaire were included in this pattern. No food or beverage items overlapped between the two patterns.

\section{Statistical analysis}

Person-years of follow-up were counted from the date of recruitment to the date of diagnosis of colorectal cancer, death, migration, or 31 December 2005, whichever occurred first. Proportional hazards regression methods were used to examine the associations between dietary exposure levels and colorectal cancer risk, measured by hazard ratios (HRs) and their corresponding 95\% confidence intervals (CIs) (Cox, 1972). Study participants were grouped into quartiles based on the distribution among the entire cohort. The linear trend tests for dietary pattern - cancer associations were based on ordinal values of the quartiles $(0,1,2,3)$. In all analyses, we adjusted for the following potential confounders: sex, age at baseline interview (years), year of interview (1993-1995, 1996-1998), dialect group (Cantonese, Hokkien), the level of education (no formal education, primary school, secondary school, or higher), cigarette smoking ('heavy' = started to smoke before the age of 15 years and smoked $\geqslant 13$ cigarettes per day, 'light' $=$ all non-heavy smokers, never) (Tsong et al, 2007), alcohol consumption (nondrinker, $<7$ drinks per week, $\geqslant 7$ drinks per week) (Tsong et al, 2007), body mass index $\left(<20,20-23.9,24-27.9, \geqslant 28 \mathrm{~m} \mathrm{~kg}^{-2}\right)$, familial history of colorectal cancer (no, yes first-degree relative), diabetes at baseline (no, yes) (Seow et al, 2006), any weekly physical activity (no, yes).

Table I Single nutrient and food associations with colorectal cancer

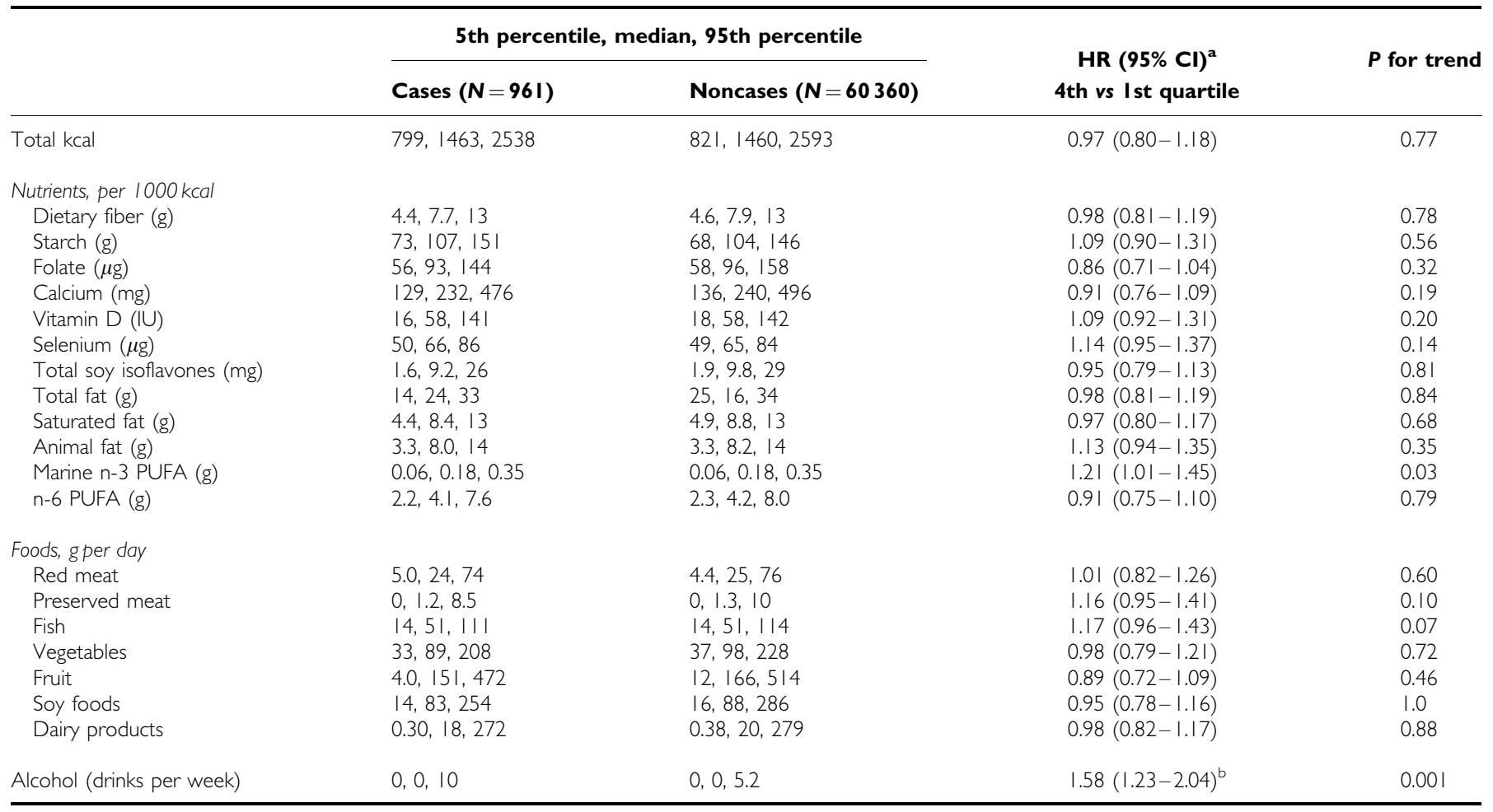

$\mathrm{Cl}=$ confidence interval. ${ }^{a} \mathrm{All}$ hazard ratios (HRs) were adjusted for age at interview (year), sex, dialect group (Cantonese, Hokkien), interview year (1993-1995, 1996-1998), diabetes at baseline (no, yes), smoking history (never, 'heavy' or $\geqslant 13$ cigarettes per day starting age $<15$ years, 'light' or non-heavy smokers), body mass index ( $<20,20-23.9$, $\left.24-27.9, \geqslant 28 \mathrm{~m} \mathrm{~kg}^{-2}\right)$, alcohol intake $(0,<7, \geqslant 7$ drinks per week), education (no formal education, primary school, secondary school, or higher), any weekly physical activity (no, yes), first-degree relative diagnosed with colorectal cancer (no, yes), and total daily energy intake (kcal). ' $\mathrm{HR}$ for $\geqslant 7$ drinks per week vs nondrinker. 


\section{RESULTS}

The Singapore Chinese diet consists primarily of mixed dishes that are generally high in refined carbohydrates (e.g., noodles and white rice), soyfoods, and green leafy vegetables, and contain relatively small quantities of meats, such as chicken and pork. Indicative of a population in transition from low to high socioeconomic status, we observed a wide distribution of intake for traditional (e.g., fish and soy) and non-traditional (e.g., red meat and dairy) foods (Table 1). With the exception of a positive association with marine n-3 PUFA and alcohol intake, none of the nutrients or foods was associated with colorectal cancer (Table 1).

Individuals among the fourth quartile of the meat-dim sum pattern were more likely to be male, have higher education, report any weekly physical activity, be a heavy smoker, drink alcohol, and consume more saturated fat, compared to individuals in the first quartile (Table 2). Similar trends by education level and physical activity were observed between fourth and first quartiles of fruitvegetable-soy pattern intake. In contrast, individuals in the fourth fruit-vegetable-soy quartile were less likely to be heavy smokers, and more likely to consume marine n-3 and total n-6 PUFAs.

We observed no association between quartiles of the meat-dim sum or vegetable-fruit-soy dietary patterns and risk of colorectal cancer, overall or by stage of disease (Table 3). With the meat-dim sum pattern, there were no differences in HRs for fourth $v s$ first quartile by subsite $(\mathrm{HR}=0.95,95 \% \mathrm{CI}$ : $0.72-1.25$ for colon; $\mathrm{HR}=1.04,95 \%$ CI: $0.73-1.49$ for rectum $)$, or by sex $(\mathrm{HR}=0.95$, 95\% CI: $0.72-1.26$ for men; $\mathrm{HR}=0.96,95 \%$ CI: $0.68-1.37$ for women). Similarly, there was no association with the vegetablefruit-soy pattern, regardless of subsite or sex (data not shown). No effect modification of either dietary pattern was observed by body mass index, physical activity, education level, or baseline diabetes (data not shown).

\section{DISCUSSION}

Using nearly 10 years of follow-up data from our Singapore Chinese cohort, we observed no association with dietary patterns for colorectal cancer. Our findings contribute to the few prospective studies of dietary patterns and cancer risk among Asian populations (Kim et al, 2005; Cui et al, 2007). Our finding of no association with a dietary pattern characterised primarily by vegetable intake is consistent with most prospective findings for similar dietary patterns among Japanese (Kim et al, 2005), US (Fung et al, 2003; Wu et al, 2004), and Western European (Dixon

Table 2 Baseline characteristics by dietary pattern quartiles $(\mathrm{Q})$

\begin{tabular}{|c|c|c|c|c|}
\hline & \multicolumn{2}{|c|}{ Meat - dim sum } & \multicolumn{2}{|c|}{ Vegetable - fruit - soy } \\
\hline & QI & Q4 & QI & Q4 \\
\hline Median age (interquartile range) years & $59(13)$ & $53(11)$ & $57(14)$ & $54(12)$ \\
\hline Male (\%) & 31.2 & 59.6 & 47.9 & 43.4 \\
\hline Hokkien dialect group (\%) & 56.0 & 52.9 & 58.9 & 50.1 \\
\hline Primary education & 41.8 & 45.6 & 44.1 & 43.9 \\
\hline Secondary education or higher & 20.4 & 37.1 & 21.7 & 34.6 \\
\hline \multicolumn{5}{|l|}{ Body mass index, kg per m² (\%) } \\
\hline$<20.0$ & 15.2 & 15.5 & 15.7 & 15.3 \\
\hline $20.0-24.0$ & 56.7 & 52.1 & 56.1 & 52.2 \\
\hline $24.1-28.0$ & 21.4 & 24.8 & 21.4 & 25.3 \\
\hline \multicolumn{5}{|l|}{ Smoking index (\%) } \\
\hline Never & 77.4 & 60.7 & 62.0 & 73.7 \\
\hline Light & 20.0 & 34.2 & 32.9 & 23.4 \\
\hline Heavy & 2.7 & 5.1 & 5.0 & 2.9 \\
\hline \multicolumn{5}{|l|}{ Alcohol consumption (\%) } \\
\hline Nondrinkers & 90.9 & 68.9 & 81.5 & 79.4 \\
\hline$<7$ drinks per week & 7.1 & 22.6 & 12.6 & 16.1 \\
\hline$\geqslant 7$ drinks per week & 2.0 & 8.5 & 5.9 & 4.4 \\
\hline \multicolumn{5}{|l|}{ Green tea intake (\%) } \\
\hline None & 67.2 & 50.9 & 69.7 & 48.6 \\
\hline Monthly & 10.1 & 12.4 & 10.3 & 12.3 \\
\hline Weekly & 12.5 & 22.2 & 10.9 & 23.3 \\
\hline
\end{tabular}


Table 3 Hazard ratios (HR) for dietary pattern quartiles $(Q)$ in relation to colorectal cancer by stage of disease

\begin{tabular}{|c|c|c|c|c|}
\hline & QI & Q2 & Q3 & Q4 \\
\hline \multicolumn{5}{|c|}{ Meat-dim sum pattern } \\
\hline \multicolumn{5}{|c|}{ Colorectal cancer } \\
\hline Cases, N & 277 & 250 & 225 & 209 \\
\hline$H R^{\mathrm{a}}$ & 1.0 & 1.01 & 0.98 & 0.97 \\
\hline $95 \% \mathrm{Cl}$ & & $0.85-1.21$ & $0.81-1.18$ & $0.78-1.20$ \\
\hline \multicolumn{5}{|c|}{ Localised disease } \\
\hline Cases, N & 96 & 94 & 107 & 79 \\
\hline$H R^{a}$ & 1.0 & 1.09 & 1.30 & 0.99 \\
\hline $95 \% \mathrm{Cl}$ & & $0.81-1.45$ & $0.97-1.74$ & $0.69-1.41$ \\
\hline \multicolumn{5}{|c|}{ Advanced disease } \\
\hline Cases, N & $|6|$ & 140 & 107 & 119 \\
\hline$H R^{a}$ & 1.0 & 0.98 & 0.81 & 0.99 \\
\hline $95 \% \mathrm{Cl}$ & & $0.78-1.24$ & $0.62-1.05$ & $0.74-1.32$ \\
\hline \multicolumn{5}{|c|}{ Vegetable-fruit-soy pattern } \\
\hline \multicolumn{5}{|c|}{ Colorectal cancer } \\
\hline Cases, $N$ & 283 & 243 & 224 & 211 \\
\hline$H R^{a}$ & 1.0 & 1.00 & 1.01 & 1.02 \\
\hline $95 \% \mathrm{Cl}$ & & $0.84-1.19$ & $0.84-1.21$ & $0.83-1.24$ \\
\hline \multicolumn{5}{|c|}{ Localised disease } \\
\hline Cases, N & 101 & 88 & 98 & 89 \\
\hline$H R^{a}$ & 1.0 & 1.01 & 1.22 & 1.16 \\
\hline $95 \% \mathrm{Cl}$ & & $0.75-1.34$ & $0.91-1.62$ & $0.84-1.59$ \\
\hline \multicolumn{5}{|c|}{ Advanced disease } \\
\hline Cases, $N$ & 161 & 143 & 114 & 109 \\
\hline $\mathrm{HR}^{\mathrm{a}}$ & 1.0 & 1.04 & 0.92 & 0.95 \\
\hline $95 \% \mathrm{Cl}$ & & $0.82-1.30$ & $0.71-1.18$ & $0.73-1.25$ \\
\hline
\end{tabular}

$\mathrm{Cl}=$ confidence interval. ${ }^{\mathrm{a}} \mathrm{All} \mathrm{HRs}$ were adjusted for age at interview (year), sex dialect group (Cantonese, Hokkien), interview year (1993-1995, 1996-1998), diabetes at baseline (no, yes), smoking history (never, 'heavy' or $\geqslant 13$ cigarettes per day starting age $<15$ years, 'light' or non-heavy smokers), body mass index $(<20$, $\left.20-23.9,24-27.9, \geqslant 28 \mathrm{~m} \mathrm{~kg}^{-2}\right)$, alcohol intake $(0,<7, \geqslant 7$ drinks per week) education (no formal education, primary school, secondary school, or higher), any weekly physical activity (no, yes), first-degree relative diagnosed with colorectal cancer (no, yes), and total daily energy intake (kcal).

et al, 2004) populations. However, our finding of no association with our meat-based pattern was not consistent with most previous studies.

Our meat-dim sum pattern was similar to the 'Western' dietary pattern, previously characterised by red and processed meats, sweets and desserts, French fries, refined grains (Fung et al, 2003). Positive associations have been reported among most (Fung et al, 2003; Dixon et al, 2004; Kesse et al, 2006; Flood et al, 2008), but not all (Terry et al, 2001; Wu et al, 2004) US and Western European cohorts. Among the Japanese cohort, no association was observed with the Western pattern and colorectal cancer overall, but a positive association with a non-statistically significant trend was observed for colon cancer among women (Kim et al, 2005).

Perhaps there is more convincing evidence for a positive association with a Western dietary pattern among non-Asian populations, because the pattern is more strongly correlated with other colorectal cancer risk factors, such as obesity and physical inactivity. Differences in meat cooking methods between Western and Asian populations may be another reason for the discrepancy. For example, in the US consuming grilled meat is a major source of exposure to the colorectal mutagens, heterocyclic amines (Bogen and Keating, 2001), whereas these are at non-detectable levels among Chinese populations, where stir frying is the preferred meat cooking method (Turesky et al, 2007).
These and previous findings from the Singapore Chinese cohort do not support hypotheses that dietary factors, whether as single nutrients, foods, or as dietary patterns, are major contributors to the recent rise in colorectal cancer risk in this population. Individual dietary factors with evidence for a role in colorectal cancer include red meat, preserved red meat, and alcohol as risk factors; and dietary fiber, garlic, dairy products, and calcium as preventive factors (World Cancer Research Fund/American Institute for Cancer Research, 2007). Of these factors, only alcohol intake was associated with colorectal cancer in our data (Tsong et al, 2007). Neither alcohol nor the other dietary risk factors that we have identified in our data, such as saturated and marine n-3 polyunsaturated fatty acids (Butler et $a l$, in press) and green tea (Sun et al, 2007), are likely to explain the recent colorectal cancer trends among Singapore Chinese population.

As an alternative hypothesis, we propose that the rise in type 2 diabetes mellitus (T2D) prevalence in Singapore (Cheah et al, 1985; Ministry of Health, 1998) is a major contributing factor to the parallel rise in colorectal cancer risk. We have reported a modest positive association between T2D and colorectal cancer (Seow et al, 2006). We have also observed a monotonic increase in risk of developing T2D across the spectrum of body mass index, with a moderate association for those among the second decile $(\mathrm{HR}=1.70 ; \quad 95 \% \quad \mathrm{CI}=1.20-2.41$, for $18.8-20.2$ vs $11.6-$ $\left.18.8 \mathrm{~kg} \mathrm{~m}^{-2}\right)$ up to a HR of 7.80 (95\% CI: $\left.5.80-10.48\right)$ for the top decile (Odegaard et al, 2006). Possible underlying biologic mechanisms by which insulin resistance may cause colorectal cancer include stimulating proliferation and reducing apoptosis in colon cells, inducing change in cell signalling pathways, such as protein kinase- $\mathrm{C}$ and mitogen-activated protein kinase, and alterering the insulin growth factor system, which is responsible for cell growth and differentiation (reviewed by Gunter and Leitzmann, 2006).

The limitations of principal components analysis include the subjective nature of determining the number of patterns, labelling the patterns, and interpreting these patterns (Martinez et al, 1998). However, we conducted sensitivity analyses and found a high degree of internal consistency and reproducibility with our patterns (Butler et al, 2006). These limitations are far outweighed by the strengths of our study, including the use of an food frequency questionnaire that was developed for and validated in our population (Hankin et al, 2001). In addition, the prospective design of our study reduced the opportunity for differential dietary recall to bias our findings.

In conclusion, neither individual nutrients or foods nor dietary patterns appear to be the underlying explanation for the rise in colorectal cancer among Singapore Chinese. Population trends, in addition to a modest association with T2D in our cohort, as well as a strong underlying biologic mechanism, all suggest that factors associated with insulin resistance, such as visceral adiposity and physical inactivity, may be appropriate targets for reducing colorectal cancer incidence in the Singapore Chinese population.

\section{ACKNOWLEDGEMENTS}

This study was supported by Grants R01 CA55069, R35 CA53890, and R01 CA80205 from the National Cancer Institute, Bethesda, Maryland. Dr Butler was supported by National Institute of Child Health and Human Development's Building Interdisciplinary Research Careers in Women's Health (BIRCWH) Grant 5K12HD051958. We thank Ms Siew-Hong Low of the National University of Singapore for supervising the fieldwork of the Singapore Chinese Health Study, and Ms Kazuko Arakawa of the University of Minnesota for the development and management of the cohort study database. We also thank the Singapore Cancer Registry for assistance with the identification of cancer outcomes. 


\section{REFERENCES}

Bogen KT, Keating GA (2001) US dietary exposures to heterocyclic amines. J Expo Anal Environ Epidemiol 11: 155-168

Butler LM, Koh WP, Lee HP, Tseng M, Yu MC, London SJ (2006) Prospective study of dietary patterns and persistent cough with phlegm among Chinese Singaporeans. Am J Respir Crit Care Med 173: $264-270$

Butler LM, Wang R, Koh WP, Stern MC, Yu MC (in press) Marine n-3 and saturated fatty acids in relation to risk of colorectal cancer in Singapore Chinese: a prospective study. Int J Cancer.

Cheah JS, Yeo PP, Thai AC, Lui KF, Wang KW, Tan YT, Ng YK, Tan BY (1985) Epidemiology of diabetes mellitus in Singapore: comparison with other ASEAN countries. Ann Acad Med Singapore 14: 232 - 239

Cox D (1972) Regression models and life tables. J Roy Stat Soc B: 187-220

Cui X, Dai Q, Tseng M, Shu XO, Gao YT, Zheng W (2007) Dietary patterns and breast cancer risk in the Shanghai breast cancer study. Cancer Epidemiol Biomarkers Prev 16: $1443-1448$

Dixon LB, Balder HF, Virtanen MJ, Rashidkhani B, Mannisto S, Krogh V, van Den Brandt PA, Hartman AM, Pietinen P, Tan F, Virtamo J, Wolk A, Goldbohm RA (2004) Dietary patterns associated with colon and rectal cancer: results from the Dietary Patterns and Cancer (DIETSCAN) Project. Am J Clin Nutr 80: 1003-1011

Flood A, Rastogi T, Wirfalt E, Mitrou PN, Reedy J, Subar AF, Kipnis V, Mouw T, Hollenbeck AR, Leitzmann M, Schatzkin A (2008) Dietary patterns as identified by factor analysis and colorectal cancer among middle-aged Americans. Am J Clin Nutr 88: 176-184

Fung T, Hu FB, Fuchs C, Giovannucci E, Hunter DJ, Stampfer MJ, Colditz GA, Willett WC (2003) Major dietary patterns and the risk of colorectal cancer in women. Arch Intern Med 163: 309-314

Gex-Fabry M, Raymond L, Jeanneret O (1988) Multivariate analysis of dietary patterns in 939 Swiss adults: sociodemographic parameters and alcohol consumption profiles. Int J Epidemiol 17: 548-555

Gunter MJ, Leitzmann MF (2006) Obesity and colorectal cancer: epidemiology, mechanisms and candidate genes. J Nutr Biochem 17: $145-156$

Hankin JH, Stram DO, Arakawa K, Park S, Low SH, Lee HP, Yu MC (2001) Singapore Chinese Health Study: development, validation, and calibration of the quantitative food frequency questionnaire. Nutr Cancer 39: $187-195$

Hatcher L (1994) A Step-by-Step Approach to using SAS for Factor Analysis and Structural Equation Modeling. SAS Institute, Inc: Cary

Kant AK, Schatzkin A, Block G, Ziegler RG, Nestle M (1991) Food group intake patterns and associated nutrient profiles of the US population. J Am Diet Assoc 91: 1532 - 1537

Kesse E, Clavel-Chapelon F, Boutron-Ruault MC (2006) Dietary patterns and risk of colorectal tumors: a cohort of French women of the National Education System (E3N). Am J Epidemiol 164: 1085-1093

Kim MK, Sasaki S, Otani T, Tsugane S (2005) Dietary patterns and subsequent colorectal cancer risk by subsite: a prospective cohort study. Int $J$ Cancer 115: $790-798$

Lv N, Cason KL (2004) Dietary pattern change and acculturation of Chinese Americans in Pennsylvania. J Am Diet Assoc 104: 771-778

Martinez ME, Marshall JR, Sechrest L (1998) Invited commentary: factor analysis and the search for objectivity. Am J Epidemiol 148: $17-19$

Maskarinec G, Novotny R, Tasaki K (2000) Dietary patterns are associated with body mass index in multiethnic women. J Nutr 130: 3068-3072
McCracken M, Olsen M, Chen Jr MS, Jemal A, Thun M, Cokkinides V, Deapen D, Ward E (2007) Cancer incidence, mortality, and associated risk factors among Asian Americans of Chinese, Filipino, Vietnamese, Korean, and Japanese ethnicities. CA Cancer J Clin 57: 190-205

Ministry of Health (1998) National Health Survey 1998. Epidemiology \& Disease Control Division: Singapore

Ministry of Health (2006) Principal Causes of Death, http://www.moh.gov.sg/ mohcorp/statistics.aspx?id = 5526:Singapore (accessed: 25 July 2008)

Ministry of Trade and Industry (2005) Growing our economy: economic history. http://app.mti.gov.sg/default.asp?id = 545:Singapore (accessed: 25 July 2008)

Odegaard A, Pereira M, Arawawa K, Koh WP, Yu M (2006) Physical activity, body mass index, and type 2 diabetes: Singapore Chinese Health Study. Am J Epidemiol 163: S187

Parkin DM, Whelan SL, Ferlay J, Teppo L, Thomas De (2003) Cancer Incidence in Five Continents. International Agency for Research on Cancer: Lyon

Randall E, Marshall JR, Graham S, Brasure J (1990) Patterns in food use and their associations with nutrient intakes. Am J Clin Nutr 52: 739-745

Seow A, Koh WP, Chia KS, Shi LM, Lee HP, Shanmugaratnam K (2004) Trends in Cancer Incidence in Singapore 1968-2002 Singapore Cancer Registry, Report No. 6

Seow A, Quah SR, Nyam D, Straughan PT, Chua T, Aw TC (2002) Food groups and the risk of colorectal carcinoma in an Asian population. Cancer 95: $2390-2396$

Seow A, Yuan JM, Koh WP, Lee HP, Yu MC (2006) Diabetes mellitus and risk of colorectal cancer in the Singapore Chinese Health Study. J Natl Cancer Inst 98: $135-138$

Slattery ML, Edwards SL, Boucher KM, Anderson K, Caan BJ (1999) Lifestyle and colon cancer: an assessment of factors associated with risk. Am J Epidemiol 150: $869-877$

Sun CL, Yuan JM, Koh WP, Lee HP, Yu MC (2007) Green tea and black tea consumption in relation to colorectal cancer risk: the Singapore Chinese Health Study. Carcinogenesis 28(10): 2143-2148

Terry P, Hu FB, Hansen H, Wolk A (2001) Prospective study of major dietary patterns and colorectal cancer risk in women. Am J Epidemiol 154: 1143 - 1149

Tsong WH, Koh WP, Yuan JM, Wang R, Sun CL, Yu MC (2007) Cigarettes and alcohol in relation to colorectal cancer: the Singapore Chinese Health Study. Br J Cancer 96: 821-827

Turesky RJ, Yuan JM, Wang R, Peterson S, Yu MC (2007) Tobacco smoking and urinary levels of 2-amino-9H-pyrido[2, 3-b]indole in men of Shanghai, China. Cancer Epidemiol Biomarkers Prev 16: 1554-1560

Wong MT, Eu KW (2007) Rise of colorectal cancer in Singapore: an epidemiological review. ANZ J Surg 77: 446-449

World Cancer Research Fund/American Institute for Cancer Research (2007) Food, Nutrition, Physical Activity, and the Prevention of Cancer: a Global Perspective, pp 280-288. AICR: Washington, DC

Wu K, Hu FB, Fuchs C, Rimm EB, Willett WC, Giovannucci E (2004) Dietary patterns and risk of colon cancer and adenoma in a cohort of men (United States). Cancer Causes Control 15: 853-862

Yuan JM, Stram DO, Arakawa K, Lee HP, Yu MC (2003) Dietary cryptoxanthin and reduced risk of lung cancer: the Singapore Chinese Health Study. Cancer Epidemiol Biomarkers Prev 12: 890-898 


\section{Appendix}

Table AI Factor loadings for foods associated with each dietary pattern: Singapore Chinese Health Study (Butler et al, 2006)

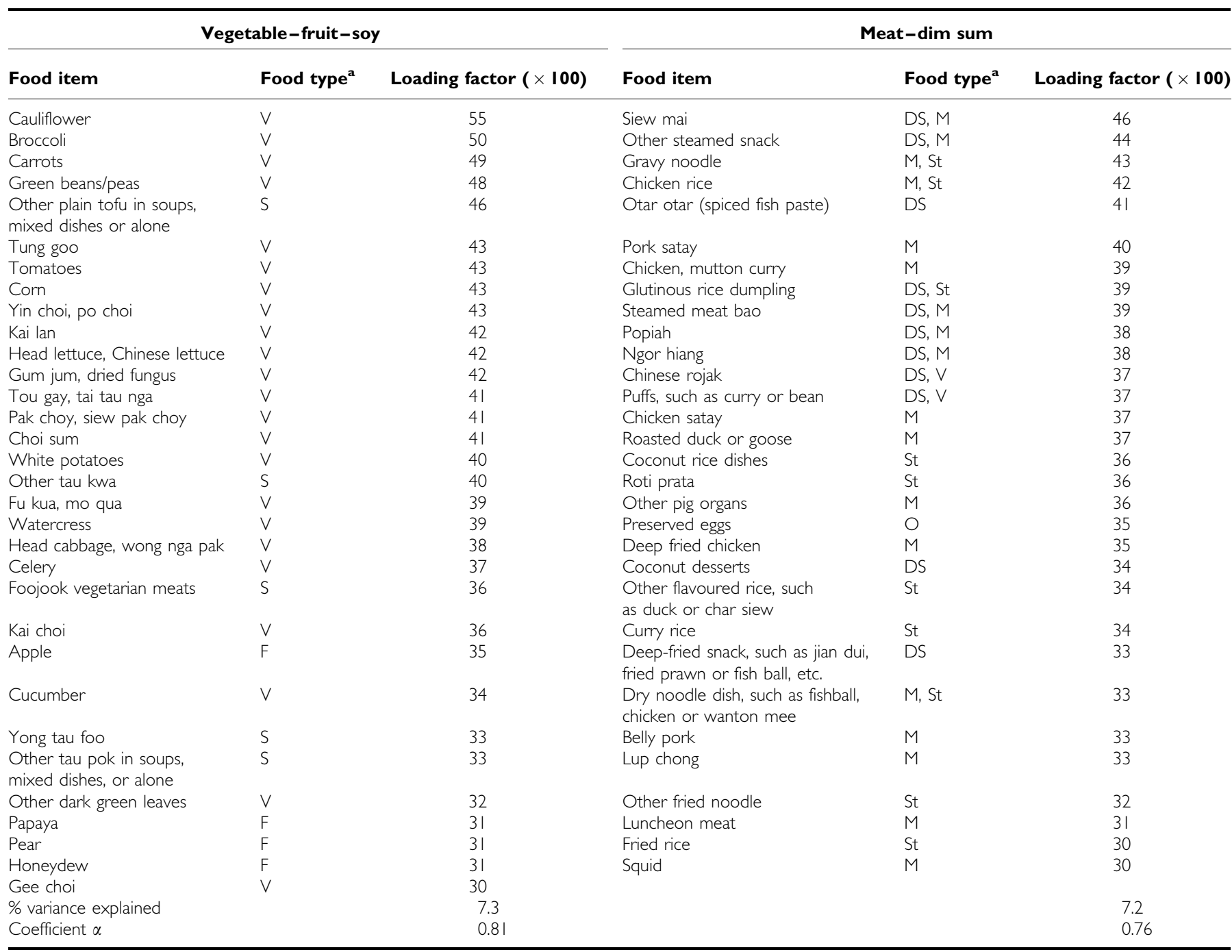

${ }^{a} V=$ vegetable, $S=$ soyfood, $F=$ fruit, $M=$ meat dish (includes fish/shellfish), $D S=\operatorname{dim}$ sum/snack dish, $S t=$ high-starch item (e.g., rice dish, noodle dish, bread), $O=$ other. 